\title{
UNDER SLEEPER PADS IN RAILWAY TRACK
}

Under sleeper pads appear to be suitable measure to improve track quality as a consequence of ballast bed protection against extreme stress. The paper comprises experience of under sleeper pads applications in the Czech Republic in two test sections which were built in the Czech Republic in 2007. The tests sections were built with the aim to protect permanent way elements against extremely high dynamic loading. That is why all parameters which could be influenced by the application of USPS are assessed, especially track quality, deflection and vibration of sleepers and bearers. Some positive influence of under sleeper pads on the track quality was observed after six years of monitoring. Extension of the application of under sleeper pads is expected in the Czech Republic especially for switches and crossings.

Keywords: Under sleeper pads, concrete sleepers, concrete bearers, switches and crossings, track quality.

\section{Introduction}

The increase of dynamic effects in railway track structures is connected with the train service speed and axle load increase. An increase of ballast stress is caused not only by the higher dynamic effects but also by the use of concrete sleepers and bearers which are characterized by higher bending stiffness and a relatively small contact area with ballast bed [1]. The dynamic effects occur due to imperfections of a railway track. The dynamic effects cause changes in sleeper or bearer support in ballast bed that unfavourably influence quality development of track geometry parameters.

A progressive deterioration of the track quality characterized by irregular supports of concrete sleepers or even by voiding sleepers which can vibrate in the ballast bed (so called dancing sleepers) as described, e.g., in [2 and 3], is a consequence of the evidence that track imperfections and higher dynamic effects are closely connected together [4] and [5].

Under sleeper pads (USPs) which are fixed on the underneath surface of a sleeper decrease the railway track stiffness. The contact area between sleepers or bearers and ballast is significantly higher. Static and dynamic loads on sleepers and bearers decrease and vehicle-track dynamic system properties are modified. Similarly, furthermore, the transfer of vibrations to a ballast bed is interrupted and damping of vibrations is moved to upper parts of a track [6], [7] and [8].

Two test sections for concrete sleepers and bearers with under sleeper pads were built in the Czech Republic in 2007 [9]. The basic motivation for the construction of the test track sections was an evaluation of the influence of under sleeper pads on improvement of track quality as a consequence of ballast bed protection against extreme stress. The paper comprises experience with applications of under sleeper pads in the Czech Republic from point of view of track settlement. Positive influence of under sleeper pads on track quality and influence on sleepers and bearers deflection and vibration was observed during six years of monitoring.

\section{Description of USP test sections}

The first test track section was built in the Plana nad Luznici railway station $\left(4^{\text {th }}\right.$ Czech railway corridor: Prague - Ceské Budejovice - Linz) in the Czech Republic in 2007. The test section comprises of a turnout J60-1:12-500-I with USPs and adjacent track. The traffic load of this track ranges from 20000 to 40000 gross tons per day.

The assembly of the USPs for the turnout was designed in the finite element model [10] with the aim to reduce abrupt changes of track vertical stiffness. The basic bedding modulus of installed

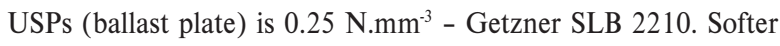
USPs - Getzner SLS 1010 and SLS 1707 - were used in the crossing panel just behind a frog nose and in the area of long bearers behind the crossing. The softer USPs are only in the middle part of the bearers. The transition zones that allow smooth transition of vertical track stiffness between the track with USPs and the track without USPs were designed. The bedding modulus of USPs in the transition zones is $0.30 \mathrm{~N} \cdot \mathrm{mm}^{-3}$ - Getzner SLB 3007. The length of the transition zone is $32.4 \mathrm{~m}$, i.e., 54 sleepers. The total length of the track with USPs is $205 \mathrm{~m}$. The pads were

\footnotetext{
* Otto Plasek, Miroslava Hruzikova, Richard Svoboda, Jaroslav Bilek

Department of Railway Structures and Constructions, Faculty of Civil Engineering, University of Technology, Brno, Czech Republic

E-mail: plasek.o@fce.vutbr.cz
} 


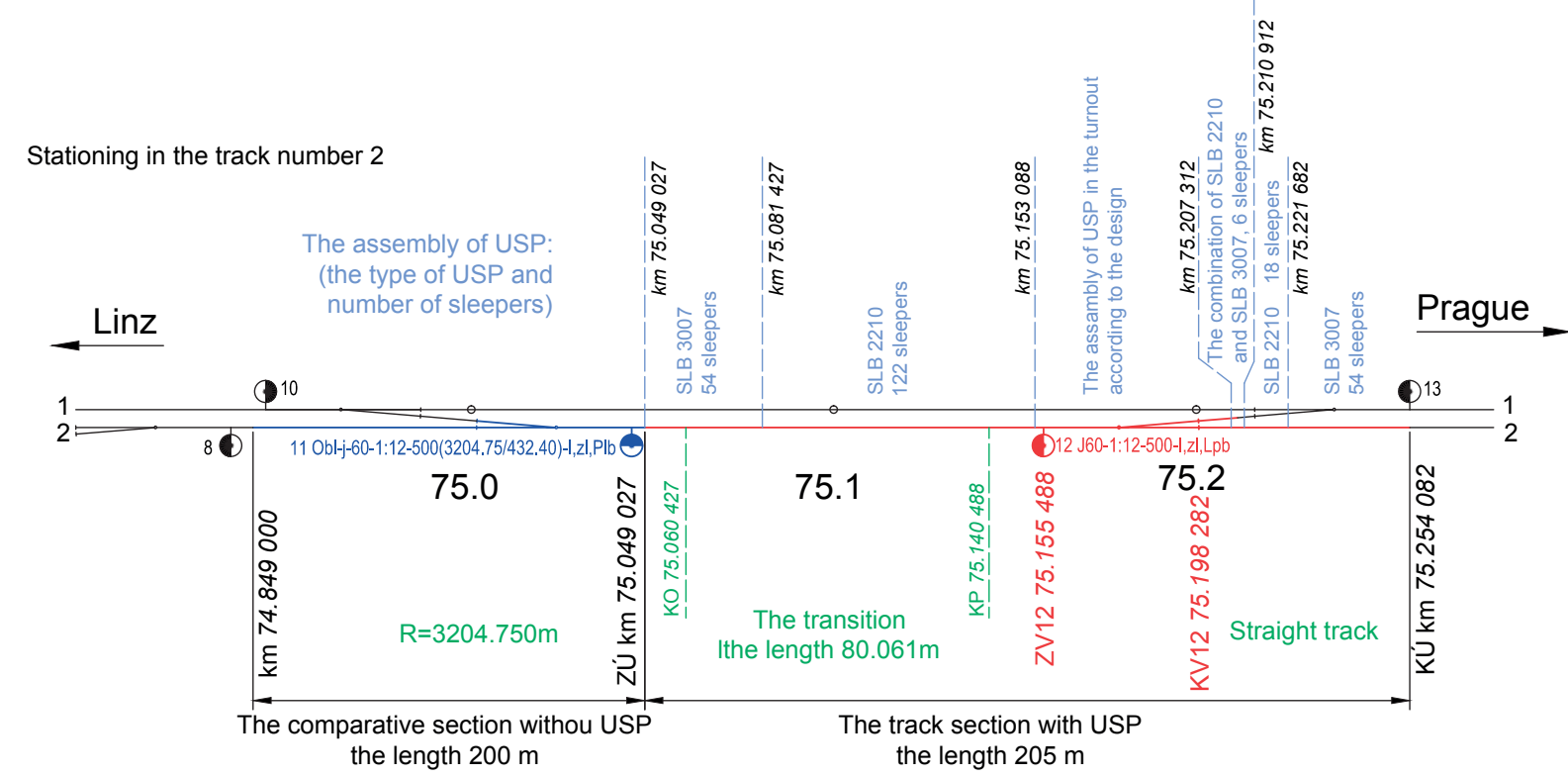

Fig. 1 The scheme of the test track section for USPS in the turnout in Plana nad Luznici railway station

installed on the underneath surface of sleepers and bearers by gluing. The neighbouring turnout and the adjacent track were chosen as a comparative conventional section. Continuous welded rail was constructed in the whole track section including both turnouts. The review of the whole test section is in Fig. 1.

Discrepancies between the assembly design of USPs and its installation (lacking USPs, wrong glued-on USPs) were found out after the turnout had been laid on $9^{\text {th }}$ November 2007. Speed restriction was imposed. The discrepancies reparation was finished on $7^{\text {th }}$ April 2008 and the speed restriction was removed after the tamping of the turnout and the ballast consolidation. The tamping was carried out three times in the test track section: $6^{\text {th }}$ April 2008 (during reparation works, only the turnout with USP), $12^{\text {th }}$ November 2008 (only the turnout with USP) and $23^{\text {rd }}$ July 2009.

In 2007 the second test section in the Czech Republic was constructed in a curve of tight radius with the primary aim to evaluate the influence of USPs on reduction of rail corrugation development and, consequently, on the quality of track geometry parameters worsening. Test section was built in Havlickuv Brod

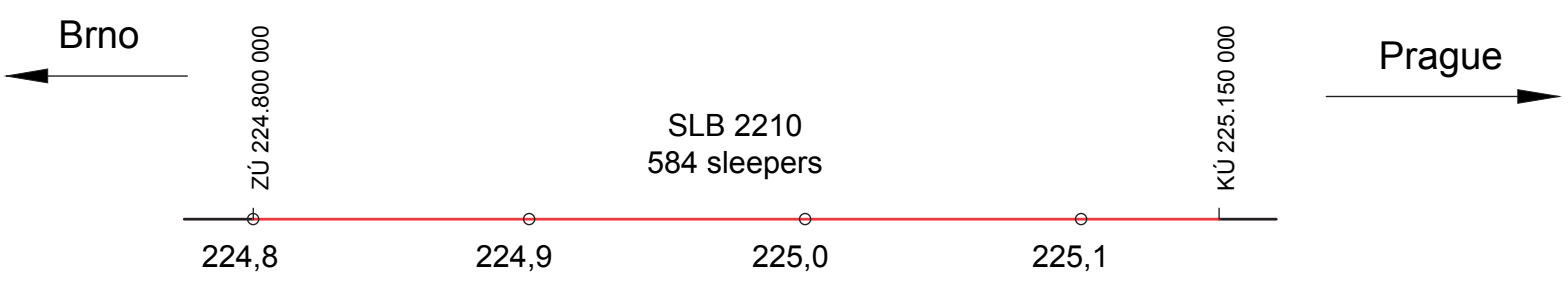

The alignment of the line

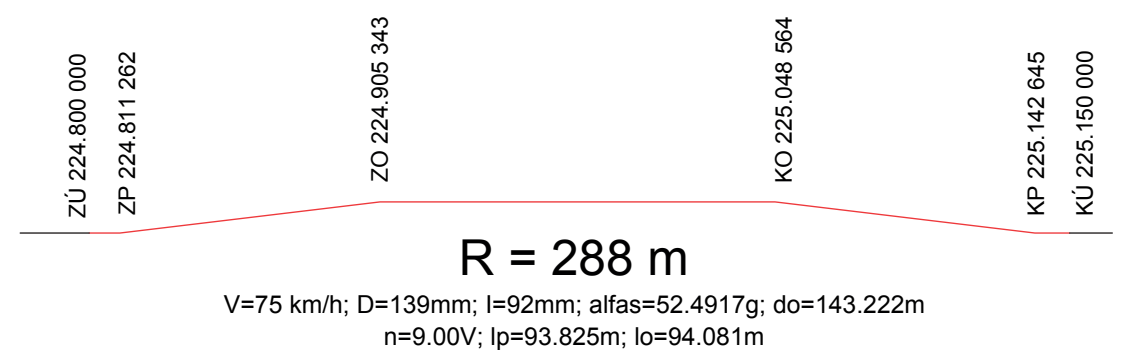

Fig. 2 The scheme of Havlickuv Brod-Okrouhlice test track section for USPS 
- Okrouhlice (the second main line Prague - Brno) track section in track No. 1 in length of $350 \mathrm{~m}$. The curve radius is $R=288 \mathrm{~m}$, speed $V=75 \mathrm{~km} \cdot \mathrm{h}^{-1}$ and cant $D=139 \mathrm{~mm}$, see Fig. 2. The section is partially on an embankment, partially in the cut and includes track on two bridges. Rail 49 E1, fastening Vossloh W 14 and sleepers B 91S (the Czech design and product) were installed in the section. Rail fastening with high elasticity Vossloh E 14 is installed in adjacent track and in track No. 2. The design track vertical stiffness in the case of E 14 fastening and sleepers without USPs is almost the same as the vertical stiffness of track with W 14 rail fastening and sleepers with USP. Therefore, no transition zones were constructed in this test section. The static bedding modulus of USPs (ballast plate) is $0.25 \mathrm{~N} . \mathrm{mm}^{-3}$ - Getzner SLB 2210.

\section{Monitoring of USP test sections}

\subsection{Review of monitored parameters}

The tests sections were built with the aim to protect permanent way elements against extremely high dynamic loading. That is why all parameters that could be influenced by the application of USPs are assessed. The following parameters are being observed:
- quality of track geometry parameters;

- track settlements;

- vertical deflections under a running axle;

- vibrations of railway superstructure elements;

- transfer of vibrations to a track vicinity;

- noise propagation to a track vicinity.

This article deals with the track settlement monitoring by precise levelling. The aim of this assessment is to verify the stability of the support of sleepers and the long bearers with USPs in ballast bed.

\subsection{Track level and settlement - precise levelling}

The height of running surface of both rails was monitored through a precise levelling. Rail levels, bracket-type datum mark heights and other check points were monitored. Ninety three sections within $74.848-75.282 \mathrm{~km}$ are being monitored in the Plana nad Luznici track section. The length of sections in the track between the turnouts has the distance of $6 \mathrm{~m}$; the sections in the turnouts have the distance of $3 \mathrm{~m}$. Seventy four sections were established within $224.770-225.208 \mathrm{~km}$ in the step of $6 \mathrm{~m}$ in the Havlickuv Brod - Okrouhlice track section.

The track level is evaluated in a relative altitude system. Relative deviations from the optimized track position, which was

\section{Settlement relatively to the track level 19. 8. 2009 (last tamping 23. 7. 2009)}

VI - 19. 8. 2009; VII - 27. 11. 2009; X - 8. 12. 2010; XIII - 25. 11. 2012, XVI - 30. 11. 2012; XIX - 22. 11. 2013

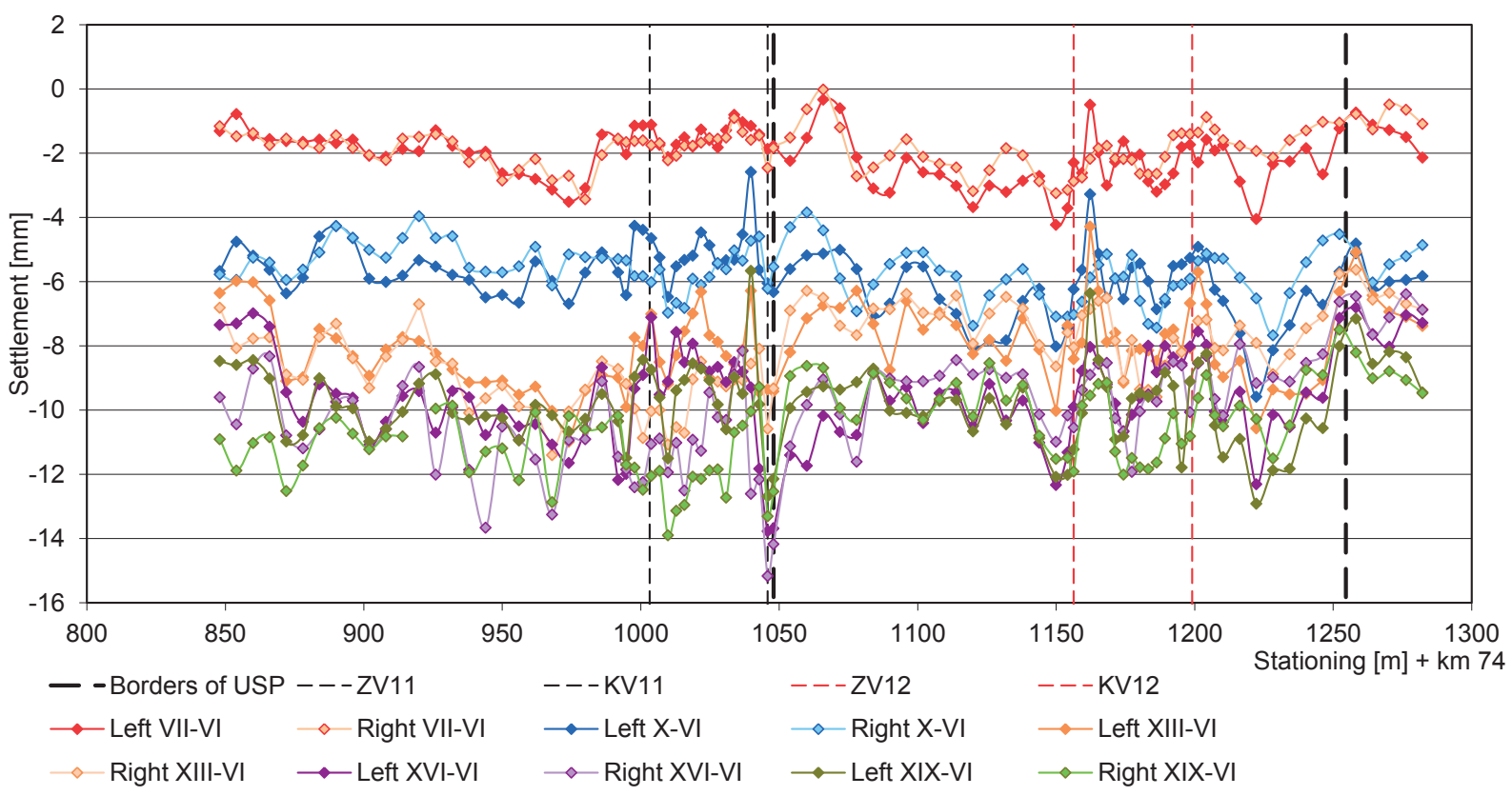

Fig. 3 The track settlement in Plana nad Luznici after track tamping (23 July 2009) relatively to the track level of 19 August 2009 ( $Z V$ - front joint of turnout, $K V$ - heel joint) 
Track twist 22. 11. 2013

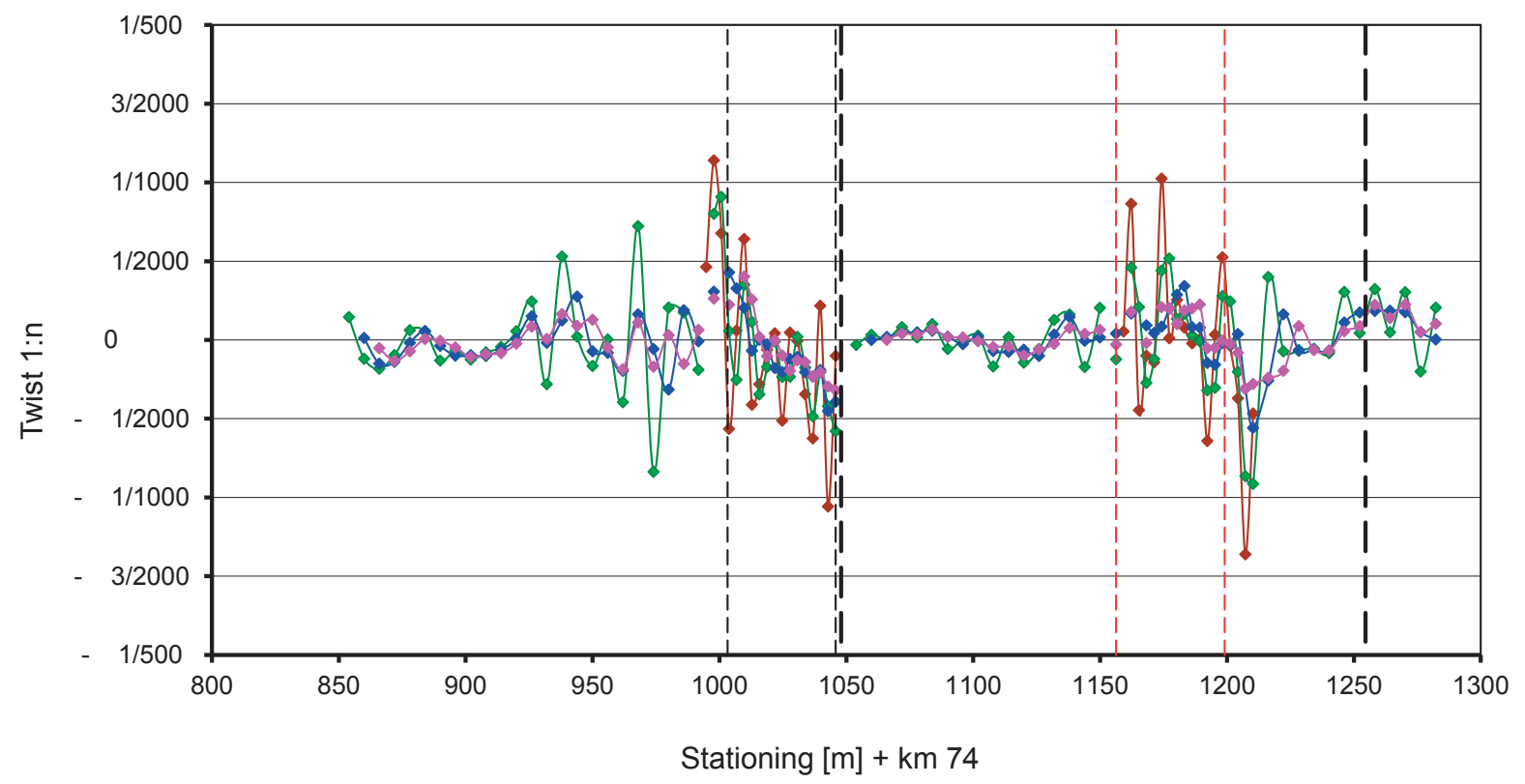

$\rightarrow 3 \mathrm{~m} \quad \multimap 6 \mathrm{~m} \quad \rightarrow-12 \mathrm{~m} \quad \longrightarrow-18 \mathrm{~m} \quad-$-Borders of USP $\quad---\mathrm{KV} 11 \quad---\mathrm{ZV} 11 \quad---\mathrm{ZV} 12 \quad---\mathrm{KV} 12$

Fig. 4 Track twist in Plana nad Luznici over the length of $3 \mathrm{~m}, 6 \mathrm{~m}, 12 \mathrm{~m}$ and $18 \mathrm{~m} ; 22$ November 2013

Settlement relatively to the track level 5.12. 2008 (last tamping 6. 10. 2008)

IV - 5. 12. 2008; VII - 27. 11. 2009; X - 8. 12. 2010; XVI - 30. 11. 2012; XIII - 25. 11. 2011; $\mathrm{XIX}$ - 22. 11. 2013

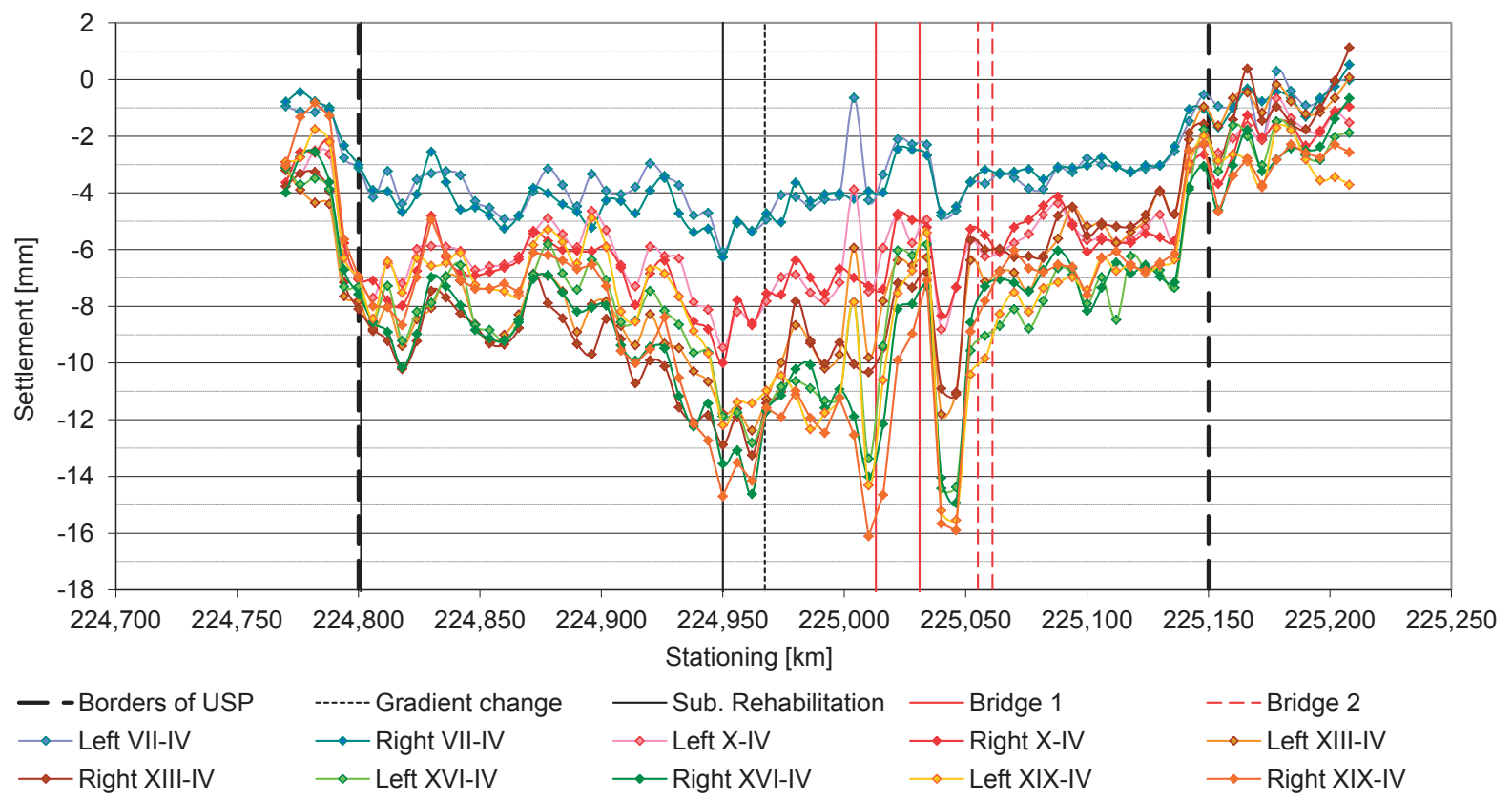

Fig. 5 The track settlement in Havlickuv Brod - Okrouhlice test track section after track tamping relatively to the track level of the 5 December 2008 
found out by regression in the initial observation, were calculated. Designed parameters of height curves were taken into account. The evaluation of relative geometry parameters - settlement, track twist - was chosen for two reasons. The first reason is the fact that a printing of absolute track level in a chart doesn't provide an evidence of the track level deviation which is relatively tight to the absolute track level. An expression of the deviation relative to the designed track level is influenced by overall changes of the track level in the whole section - settlement or tamping of the track which is the second reason. Deviations from relative designed position, track twist in a few wavelengths and a progress of track settlement were calculated.

The longitudinal level of the track in both test track sections was measured three times every year after the test sections had been put into operation. There is an evident local extreme of settlement in the vicinity of heel joint of turnout No. 11 in Plana nad Luznici without USPs in relative stationing of $1050 \mathrm{~m}$, see Fig. 3. The local extreme is caused by unsymmetrical settlement of bearer in the crossing panel and just behind it. The undesirable unsymmetrical settlement is the main reason for the USPs installation on bearers. Such local extreme doesn't appear in the crossing panel in turnout No. 12 with USPs. It can be stated that the installation of USPs in this test track section is a preventive measure improving the track quality.

Next important parameter of track quality is the track twist. The track twist was calculated from computed cant. The distance of the measurement points is either $3 \mathrm{~m}$ (in the turnouts) or $6 \mathrm{~m}$ (for the points out of the turnouts). Therefore, the twist was calculated for the track length of $3 \mathrm{~m}$ (only in turnouts), $6 \mathrm{~m}, 12 \mathrm{~m}$ and $18 \mathrm{~m}$. The twist for the last measurement is to be found in Fig. 4. The influence of USPs is obvious from the results, mainly for the track between turnouts. The track twist for unloaded track in turnouts is roughly the same. Here, the discrepancies during construction of turnout No. 12 with USPs, which are described above, influence the evaluation of track twist.

A significantly higher settlement is evident for the track with USPs in comparison to the track without USPs and elastic fastening Vossloh E 14 in Havlickuv Brod - Okrouhlice test section, see Fig. 5. Both bridges dominantly influence settlement of the track and local extremes of the track settlement occur just in transition zones of the bridges.

\subsection{Evaluation of track settlement}

The settlement progress analysis in both sections for plain track with and without USPs was carried out. The exponential regression of settlement curves was calculated by least square method following the formula:

$S(l)=L \cdot\left(1-e^{-\frac{k}{L} \cdot l}\right)$ in which symbols mean:

$S_{(l)} \ldots$ function of settlement [mm];

$l \quad \ldots$ service load [MGT ... million gross tons];

$L \quad$... limit of settlement [mm];

$k \quad$... slope of tangent at $1=0\left[\mathrm{~mm} \cdot \mathrm{MGT}^{-1}\right]$.

The regression functions were determined by least square method to find the minimum of the function:

$\min \left\{f(x): x \in X \subset E^{2}\right\}$

in which:

$\begin{array}{lll}x & \ldots & \text { vector of parameters of the regression function }[k L]^{\mathrm{T}} \text {; }\end{array}$

$X \quad$... subset defined by constraints $k>0$ and $L>0$ of Euclidean space $E^{2}$.

The function $f(x)$ was defined:

$f(x)=\sum_{i=0}^{n}\left[s_{i}-S\left(l_{i}\right)\right]^{2}=$

$\sum_{i=0}^{n}\left[s_{i}-L\left(1-e^{-\frac{k}{L} \cdot l_{i}}\right)\right]^{2}$

in which:

$i \quad$... index of track levelling epoch;

$n \quad$... number of last epoch;

$s_{i} \quad \ldots$ measured track settlement $[\mathrm{mm}]$;

$l_{i} \quad \ldots$ service load till levelling epoch number i [MGT].

The $\min f(x)$ occurs at the point $x *$ :

$\nabla f\left(x^{*}\right)^{T}=0$

in which $\nabla f(x)$ is gradient vector:

$\nabla f(x)=\left[\frac{\partial f}{\partial k} \frac{\partial f}{\partial L}\right]$

The system of nonlinear algebraic equations was evaluated from the equation (4):

$\sum_{i=0}^{n}=\left[\left[s_{i}-L \cdot\left(1-e^{-\frac{k}{L} \cdot l_{i}}\right)\right] \cdot l_{i} \cdot e^{-\frac{k}{L} \cdot l_{i}}\right]=0$

$\sum_{i=0}^{n}=\left[\left[s_{i}-L \cdot\left(1-e^{-\frac{k}{L} \cdot l_{i}}\right)\right] \cdot\left(1+\frac{k}{L} \cdot l_{i}\right) \cdot e^{-\frac{k}{L} \cdot l_{i}}\right]=0$

The system of nonlinear equations was solved by Newton's method [11]:

$\mathrm{x}^{\mathrm{k}+1}=\mathrm{x}^{\mathrm{k}}-\left(\nabla^{2} \mathrm{f}\left(\mathrm{x}^{\mathrm{k}}\right)\right)^{-1} \cdot \nabla \mathrm{f}\left(\mathrm{x}^{\mathrm{k}}\right)$ 
in which $\nabla^{2} f(x)$ is the symmetric Hessian matrix:

$\nabla^{2} f(x)=\left[\begin{array}{cc}\frac{\partial^{2} f}{\partial k^{2}} & \frac{\partial^{2} f}{\partial k \partial L} \\ \frac{\partial^{2} f}{\partial L \partial k} & \frac{\partial^{2} f}{\partial L^{2}}\end{array}\right]$

Upper index $k$ means a step number of the numerical iteration. If convergence error was less than tolerance $\varepsilon=1.10^{-4}$, i.e.:

$$
\left\|\nabla f\left(x^{k}\right)\right\| \leq \varepsilon
$$

the calculation was stopped and the parameters $k, L$ were determined.

The average operational load is approximately 5.6 MGT per year in Plana nad Luznici section and 9.8 MGT per year in Havlickuv Brod - Okrouhlice section. The settlement progress is roughly the same for plain track with and without USPs in Plana nad Luznici test track section ( $L=10.8 \mathrm{~mm}$ without USPs, $L$ $=10.7 \mathrm{~mm}$ with USPs) and is significantly slower with rather less limit in the track in Havlickuv Brod - Okrouhlice $(L=10.1$ $\mathrm{mm}$ ), see Fig. 6. The difference in the settlement speed could be explained by the fact that in Plana nad Luznici a new subgrade structure was constructed. The settlement limit is not significant and could be omitted regarding other parameters, which influence behaviour of the track sections.

A negative relative settlement is evident for the state of monitoring before last one. This effect has not been explained completely yet. The reason can be either the limited precision of measurement and evaluation methods or influence of isolated maintenance impacts in points of the most deteriorated track level.

The progress of standard deviations of track settlement is also an interesting phenomenon. The standard deviations of settlement values, which correspond to the track quality parameters, were compared only for plain track with or without USPs in both sections, see Fig. 7. The exponential regression is again included into the chart. The significant differences between tracks with USPs and without USPs as well as differences between tracks with USPs in both sections are evident. The worsening of standard deviation in Plana nad Luznici test section almost converge but do not converge in Havlickuv Brod - Okrouhlice section where the value of standard deviation is influenced by the bridges and their transition zones. If plain track with and without USPs are compared in Plana nad Luznici for the same loading better behaviour of the track with USPs is evident.

\section{Settlement in the test sections relatively to the last tamping}

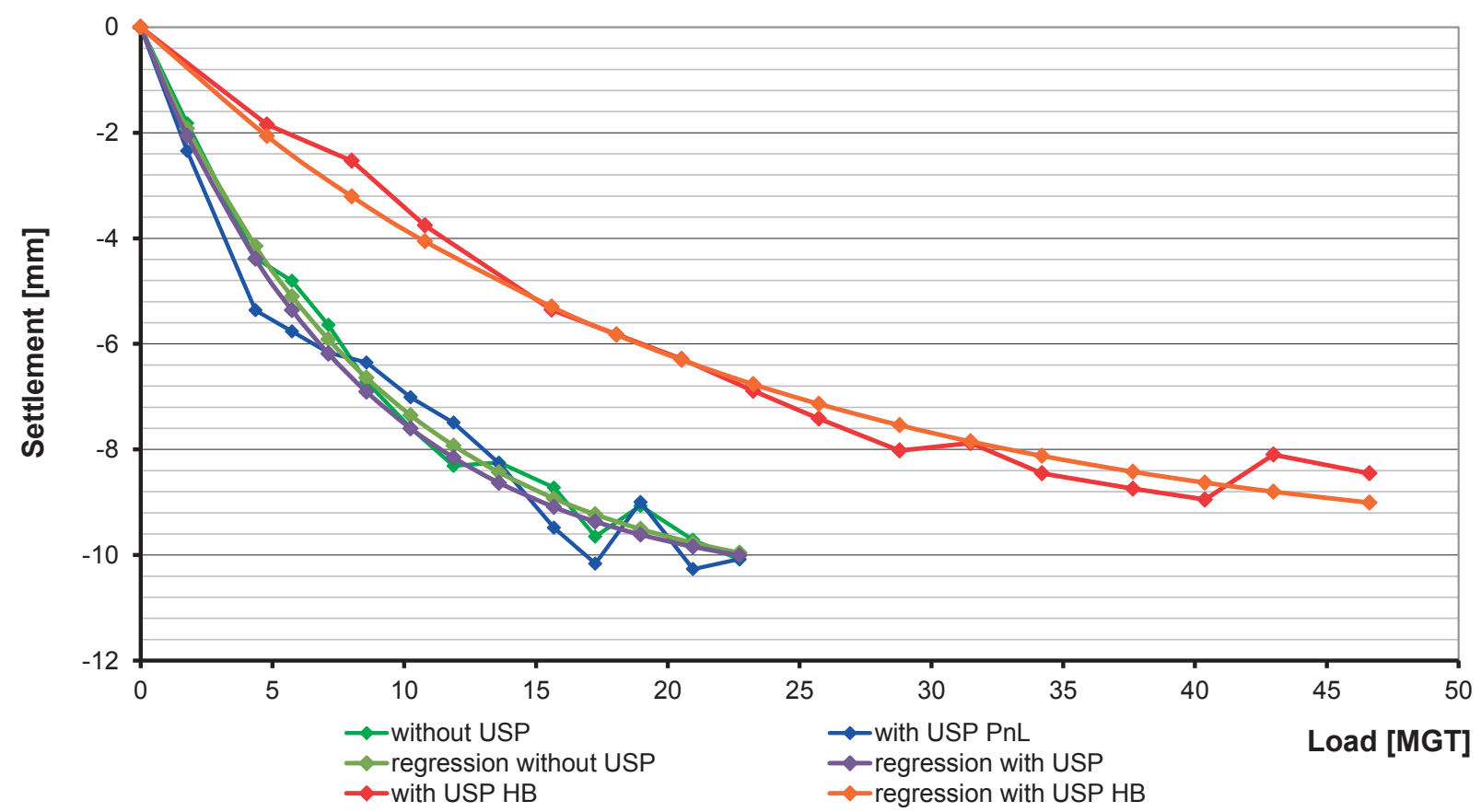

Fig. 6 Progress of settlement (PnL - Plana nad Luznici, HB - Havlickuv Brod - Okrouhlice) 


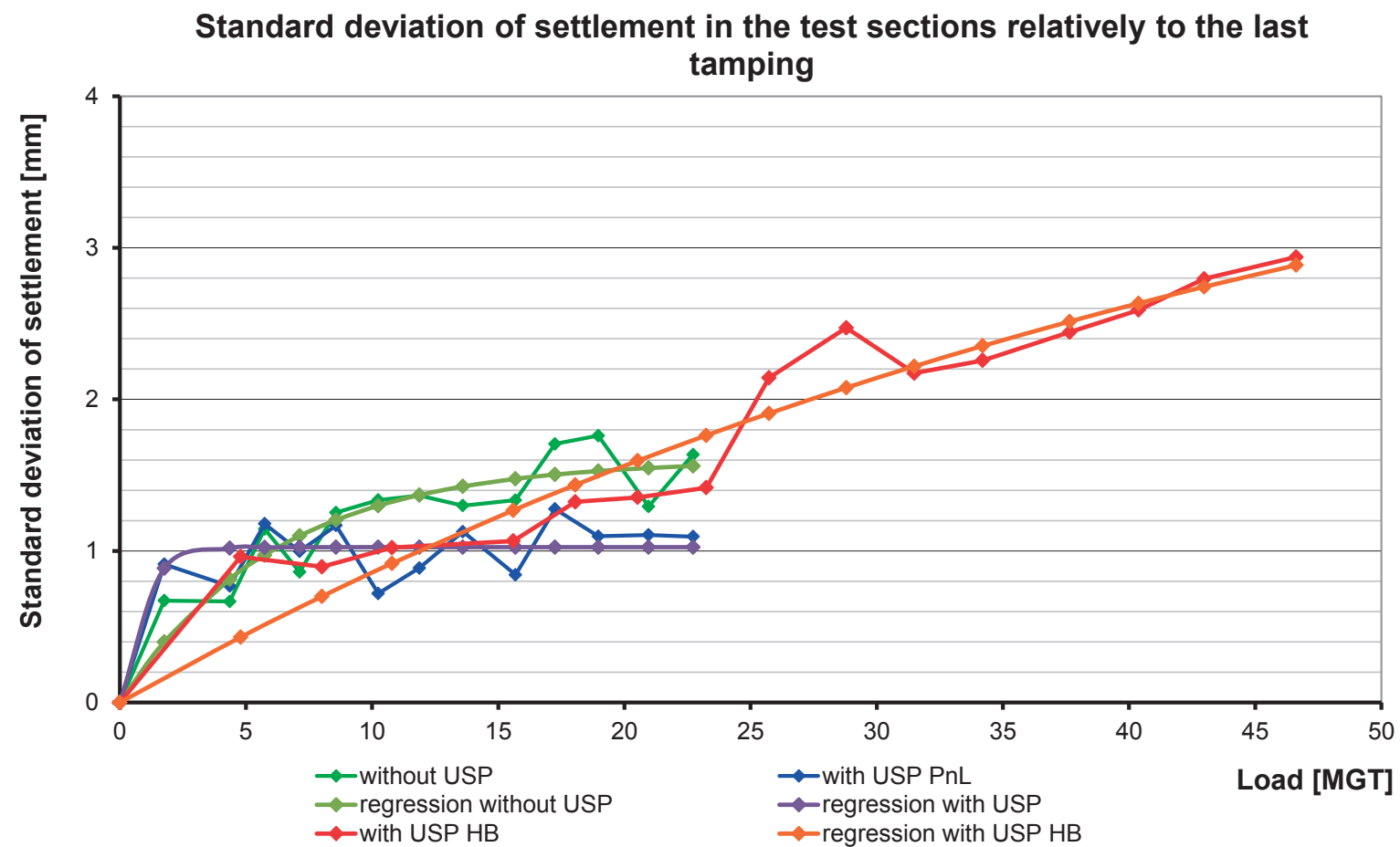

Fig. 7 Standard deviations progress of settlement (PnL: Plana nad Luznici, HB: Havlickuv Brod - Okrouhlice)

\section{Conclusion}

A summary of results of the evaluations of both track sections are following:

- the deviations of the parameters at the beginning of monitoring were comparable for both sections with and without USPs;

- the deviations in the turnouts are higher than in the plain track in general;

- USPs are efficient regarding to the quality of track geometry parameters in comparison to the track without USPs;

- the most deteriorating factor for track quality occurs on bridges and their transition zones, USPs application does not improve situation significantly;

- USPs reduce an effect of unsymmetrical settlement of long concrete bearers in the crossing panel and adjacent track;

- Vossloh E 14 rail fastening with high elasticity is more effective from the point of view of track settlement, but it needs an extra maintenance effort.

The trial track sections in the Plana nad Luznici railway station and in Havlickuv Brod - Okrouhlice track section were built with the aim to assess a USPs's influence on track geometry quality. The basic conclusions are that the track quality with USPs is better and track geometry deterioration is slower compared to the track quality without USPs. This can be explained by the reduction of stress in ballast bed under a sleeper due to the use of USPs; this phenomenon was analyzed by static and dynamic analyses by FEM [8]. As a consequence the lifetime of ballast bed is extended. The positive influence of USPs is usually evident after longer period of time considering traffic density of a track. The higher track load the sooner influence of USPs is evident and the more investment in USPs would be efficient from the point of view of life cycle costs.

The monitored data show that the influence of USPs had started to be evident two years after the USPs installation. The track settlement and deviations of track geometry parameters are lower in the section with USPs between the turnouts. It is expected that longer time period is required to get evidence of the influence of USPs in the turnout.

\section{Acknowledgement}

This outcome has been achieved with the financial support of the project of the Technology Agency of the Czech Republic No. TA01031173 Under Sleeper Pads and the project of Specific research of Brno University of Technology No. FAST-J-14-2534. 


\section{References}

[1] PLASEK, O.; HRUZIKOVA, M.: The Use of Under Sleeper Pads as a Protection of Ballast in Plain Track and Turnouts, Akustika, ISSN 1801-9064, Studio Akustika: Ceske Budejovice, 2007

[2] SCHNEIDER, P.; BOLMSVIK, R.; NIELSEN, J. C. O.: In Situ Performance of a Ballasted Railway Track with under Sleeper Pads. Proc. of the Institution of Mechanical Engineers, Part F: J. of Rail and Rapid Transit. 2011, 299-309. Available on WWW: <http:// pif.sagepub.com/content/225/3/299.full.pdf+ html>. ISSN 2041-3017 (online), 0954-4097 (print).

[3] USP - Under Sleeper Pads - Semelles sous traverses - Schwellenbesohlungen. Summarising Report of UIC Project No. I/05/U/440 [online], 4 $4^{\text {th }}$ Edition, Vienna, 2009 [cit. 2011-07-11]. S. 40. Available on WWW: <www.uic.org/IMG/pdf/2009-03-26_ Summarising_Report_UIC-USP.pdf>.

[4] IZVOLT, L.; KARDOS, J.: Influence of Parameters of Railway Track Construction on Vertical Dynamic Interaction Vehicle/ Track. Communications - Scientific Letters of the University of Zilina, No. 3, 2011, 63-70, ISSN 1335-4205

[5] BENCAT, J.; STYPULA, K.: Buildings Structure Response Due to Railway Traffic. Communication - Scientific Letters of the University of Zilina, No. 2, 2013, 41-48, ISSN 1335-4205

[6] LEYKAUF, G., STAHL, W.: Untersuchungen und Erfahrungen mit besohlten Schwellen. EI - Eisenbahningenieur, 2004, 55, 6. S. 8. ISSN 0013-2810

[7] PETIT, C.: Experience in the Field of Under Sleeper Pads, [online], Paris, France, 2006 [cit. 2011-07-11], p. 24, online: <www.uic. org/reunion.php/19039/_23_sateba_petit.pdf.

[8] POTVIN, R.: Schieneneinsenkung und Schwellenbesohlungssteifigkeit. EI - Eisenbahningenieur. 2008, 7. S. 6. ISSN 0013-2810.

[9] HRUZIKOVA, M., PLASEK, O., SMUTNY, J., SVOBODA, R., SALAJKA, V.: Trial Track Section with Under Sleeper Pads in the Czech Republic, Proc. of Railway Engineering-2009, ISBN 0-947644-65-2, Engineering Technics Press : Edinburgh, 2009

[10] PLASEK, O., HRUZIKOVA, M.: Design of Under Sleeper Pads for Turnout. Archiwum Instytutu Inzynierii Ladowej. Poznan : Archives of Institute of Civil Engineering, 2007, 241-249. ISSN 1897-4007.

[11] DALIK, J.: Numerical Methods (in Czech). Brno : CERM, 1997, 145 p. ISBN 80-214-0646-1. 